ISSN 0853-8697

\title{
ANALISA PROPAGASI GELOMBANG DALAM PANDU GELOMBANG OPTIK NONLINEAR DENGAN MEDAN SPATIAL SOLITONS
}

\author{
Harsoyono \\ Jurusan Teknik Fisika, Fakultas Teknologi Industri, Institut Teknologi Sepuluh N opember \\ Kampus ITS, Sukolilo, Surabaya 60111 \\ E-mail: harsoyono@yahoo.com
}

\begin{abstract}
The determination of field distribution of an electromagnetic wave propagating in an optically nonlinear planar waveguide with uniform medium is in priciple a two dimensional problem in the transverse plane. The associated generalized equation can be reduced to one-dimensional problems by means of effective index method, resulting in soliton likespatial distribution of the electric field along the transversal direction parallel to the waveguide plane. Taking into account this nonuniform field distribution in terms of the effective index of the guide, we have studied numerically the nonlinear coupling behaviors of a symmetric dual waveguide system. The result shows optically controlled waveguide coupling, the possibility of implementing the optically controlled logic functions.
\end{abstract}

Keywords: nonlinear optic, spatial soliton, coupling effect.

\section{PENDAHULUAN}

Pemindahan daya optik dari satu pemandu ke pemandu yang lainnya seperti dibahas pada paper sebelumnya $[4,5,7,9]$ didasarkan atas solusi dari persamaan medan dalam bentuk satu dimensi. Hal ini sangat sulit dipecahkan baik untuk mendapatkan fungsi medannya maupun nilai eigennya. Untuk solusi persamaan tersebut yang mengandung faktor nonlinear akan menghasilkan fungsi medan dalam bentuk elliptik dari fungsi Elliptic Jacobian. Sedangkan nilai eigen dari fungsi tersebut didapatkan secara numerik dari hasil analitik dari fungsi medannya. Dalam tulisan ini akan dibahas suatu teknik solusi dari persamaan medan optik nonlinear ke dalam fungsi medan linear.

Persamaan medan nonlinear dalam bentuk dua dimensi dapat dipecahkan dengan menggunakan separasi variabel, sehingga akan didapatkan bentuk dua solusi. Satu solusi merupakan fungsi medan nonlinear dalam bentuk spatial soliton, dan solusi berikutnya merupakan fungsi medan linear. Solusi dua dimensi dari satu pandu gelombang paralel dari bahan nonlinear telah banyak dianalisa yang didasarkan pada spatial solitons oleh beberapa peneliti [2,8]. Hasil dari penelitian ini hanya menunjukkan adanya perubahan sifat optik dari bahan tersebut terutama indek bias effektif dari bermacam-macam modus karena adanya pengaruh perubahan intesitas masukan. Walaupun demikian metode dari solusi tersebut dapat dikembangkan untuk menganalisa perubahan sifat optik dari dua pandu gel ombang nonlinear yang belum pernah dibahas oleh peneliti sebelumnya. 
Dalam pembahasan terdahulu telah dikemukakan bagaimana saklar optik dapat bekerja dalam dua pandu gelombang paralel dari bahan optik nonlinear yang solusinya dapat diselesaikan melalui solusi satu dimensi dengan memakai fungsi dari Jacobian Elliptic $[4,5]$. Sedangkan untuk solusi persamaan gelombang dengan dua dimensi dari medium nonlinear yang berbentuk planar (paralel) akan dapat diselesaikan dengan menggunakan pemisahan variabel. Metode ini dilakukan karena dalam persamaan gelombang nonlinear dua dimensi terdiri dari bagian linear dan nonlinear, sehingga solusi persamaan gelombang nonlionear akan di dapatkan dalam bentuk spatial soliton (soliton merupakan solusi dari persamaan gelombang nonlinear). Sedangkan solusi yang lain merupakan bentuk medan linear, dengan syarat batas kontinuitas yang dapat dilakukan secara sederhana untuk mendapatkan harga indek bias effektif dari sistem pandu gelombang tersebut. Hal ini sangat berbeda apabila solusi untuk mendapatkan indek bias effektif untuk satu variabel yang syarat batasnya hanya dapat diselesaikan melalui fungsi elliptik.

Sehingga dalam solusi dua dimensi untuk mendapatkan indek bias effektif pada setiap daya masukan dilakukan secara numerik dengan melalui iterasi berulang-ulang (sampai dicapai harga yang konvergen). Dari hasil ini akan tampak bahwa perubahan indek bias effektif sangat bergantung pada daya masukan. Untuk daya masukan yang rendah, perpindahan daya optik dari satu pemandu ke pemandu yang lain akan terjadi. Sedang untuk daya masukan yang tinggi akan diperoleh indek bias effektif yang besar, dengan demikian maka berkas masukan tersebut akan tetap tersalur dalam pandu gelombang tersebut tanpa mengalami efek pengkopelan. Atas dasar inilah maka sistem dua pandu gelombang nonlinear berbentuk paralel dapat berfungsi sebagai saklar optik.

\section{TEORI}

\subsection{Solusi dari Satu Pandu G elombang Nonlinear}

Dalam paper sebelumnya [3,5] telah dibahas solusi persamaan Helmholt satu dimensi dalam pandu gelombang nonlinear dengan struktur tiga lapis. sedang ungkapan untuk pandu gelombang gelombang nonlinear dua dimensi yang terdiri dari variable $x$ dan y sesuai medan TE dan mempunyai hubungan $E(x, y, z)=\xi(x, y)$ expi $(\beta z)$ dapat dinyatakan sebagai,

$$
\frac{\partial^{2} \xi}{\partial x^{2}}+\frac{\partial^{2} \xi}{\partial y^{2}}+\left(k_{0}^{2} n_{2}^{2}+k_{0}^{2} a|\xi|^{2}-\beta^{2}\right) \xi=0
$$

dengan $\alpha$ adalah koeffisien nonlinear $\left(\mathrm{m}^{2} / \mathrm{W}\right), \mathrm{n}_{2}$ adalah indek bias pandu gelombang (film) dan $\mathrm{n}_{2,1}=\alpha / \varepsilon_{\varepsilon_{0}} \mathrm{n}_{2}{ }^{2}$ merupakan koefisien nonlinear dengan intensitas optik $\mathrm{I}$, kemudian dilakukan pemisahan variabel secara partial dengan metode indek bias efektif [1,2]

$$
\xi(\mathrm{x}, \mathrm{y})=\psi(\mathrm{x}, \mathrm{y}) \Re(\mathrm{y})
$$

dengan mengasumsikan bahwa perubahan medan $\psi(x, y)$ terhadap y sangat kecil, maka dari persamaan (1) akan didapatkan persamaan bagian medan linear, 


$$
\frac{\partial^{2} \Re}{\partial \mathbf{y}^{2}}+\left(k_{0}^{2} N_{2}^{2}-\beta^{2}\right) \Re=0
$$

persamaan (3) merupakan persamaan eigen dengan eigen value $\beta$, sehingga bagian nonlinear untuk setiap $y=y_{i}$ dapat dituliskan sebagai,

$$
\frac{\partial^{2} \Psi}{\partial \mathrm{x}^{2}}+\mathrm{k}_{0}^{2}\left(\mathrm{n}_{2}^{2}+\mathrm{a} \Re^{2}\left(\mathrm{y}_{\mathrm{i}}\right) \Psi^{2}-\mathrm{N}_{2}^{2}\right) \Psi=0
$$

Persamaan (4) merupakan persamaan gelombang nonlinear, dan $\mathfrak{R}$ merupakan medan linear modus TE yang tidak terpengaruh oleh $x$. Untuk $-\infty<x$ $<\infty$, maka persamaan (4) tersebut dapat diselesaikan dan akan menghasilkan fungsi medan dalam bentuk spatial soliton [6]

Dari persamaan (1) dan memenuhi persamaan (3) serta melalui normalisasi medan $\mathfrak{R}$ didapatkan hubungan antara $\mathrm{N}_{2}$ dan $\beta$ yang bervariasi terhadap daya masukan $\mathrm{P}$ untuk setiap $\mathrm{y}_{i}$, yang dapat dituliskan sebagai,

$$
N_{2}{ }^{2}\left(y_{i}\right)=n_{2}{ }^{2}\left[1+\frac{n_{2}^{2} n_{2,1}^{2} k_{0}^{4} \Re^{4}\left(y_{i}\right) P^{2}}{4 \beta^{2}}\right]
$$

dimana $\mathrm{n}_{2,1}=\alpha / c_{\varepsilon_{0}} \mathrm{n}_{2}{ }^{2}$. Dari persamaan tersebut tampak bahwa harga dari $\beta$ $\left(=k_{0} N\right)$ yang dihasilkan dengsn menerspksn syarat batas kontinuitas pada persamaan (3) sangat bergantung terhadap $\mathrm{P}$, sehingga harga $\mathrm{N}_{2}$ akan bervariasi terhadap perubahan harga dari indek bias efektif $\mathrm{N}$. Sedang pengaruh perubahan indek bias efektif $\mathrm{N}$ terhadap propagasi berkas optik didalam dua pandu gelombang nonlinear akan dibahas pada pasal berikutnya.

\subsection{Efek Pengkopelan}

Kopling antara dua modus dalam pandu gelombang paralel 5 lapis dari medium nonlinear seperti yang ditunjukkan pada Gambar 1. Sehingga untuk masing-masing pemandu besarnya indek bias sangat bergantung pada intensitas optik, $n_{n l i}=n_{i}+n_{2,1} I$, dimana $n_{2,1}$ adalah koefisien nonlinear yang dalam persamaan Helmholtz diungkapkan pada persamaan (3) dan (4).

Solusi nonlinearnya telah diungkapkan pada persamaan (5) yang berhubungan dengan indek bias efektif pada persamaan linear [persamaan (3)], maka pada kedua pemandu tersebut akan terjadi efek pengkopelan antara medan $\Re_{2}(\mathrm{y})$ dan $\Re_{4}(\mathrm{y})$ akibat adanya perbedaan indek bias antara film dan substrate sebesar $\Delta \mathrm{n}_{1}$ dan $\Delta \mathrm{n}_{2}$. Secara umum persamaan medan yang terkopel diantara kedua pemandu sepanjang propagasi $z$ pada guide 1 dituliskan sebagai [6],

$$
\left[\frac{d^{2}}{d y^{2}}+\frac{d^{2}}{d z^{2}}+k_{0}^{2} n_{3}^{2}+k_{0}^{2} \Delta n_{1}^{2}+k_{0}^{2} \Delta n_{2}^{2}\right] \Phi(y, z)=0
$$

dengan $\Phi(y, z)$ merupakan kombinasi medan linear dari medan didalam kedua pandu gelombang [6], sehingga persamaan modus terkopel dari pandu gelombang simetris hanya merupakan solusi linear yang dinyatakan sebagai,

$$
\begin{aligned}
& d a_{1}(z) / d z=-i K_{2} a_{2}(z) \\
& d a_{2}(z) / d z=-i K_{2} a_{1}(z)
\end{aligned}
$$




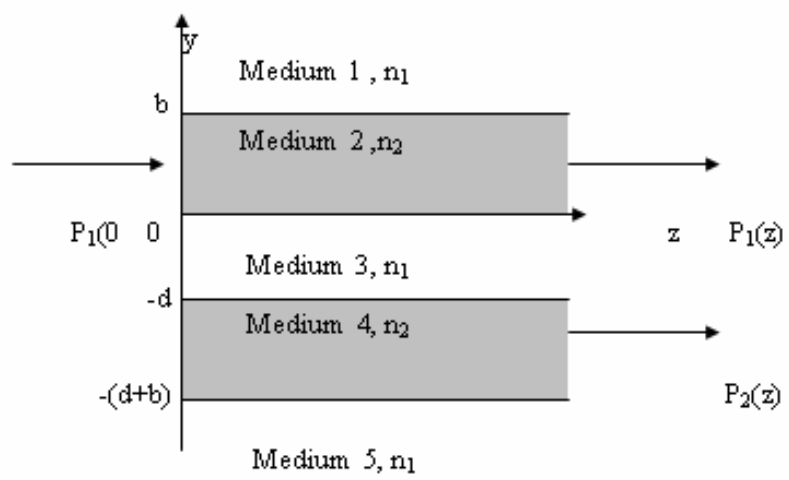

Gambar 1. Struktur pandu gel ombang nonlinear directional coupler

dengan $a_{1}(z)=A_{1}(z) \exp \left(i K_{1} z\right), a_{2}(z)=A_{2}(z) \exp \left(i K_{1} z\right)$ sedang $K$ adalah koeffisien kopling linear yang didifinisikan sebagai,

$$
\mathrm{K}_{1}=\omega \varepsilon \varepsilon_{0} \iint \Re_{2}{ }^{*}(\mathrm{y}) . \Delta \mathrm{n}_{2}{ }^{2} \Re_{2}(\mathrm{y}) \mathrm{dy} ; \mathrm{K}_{2}=\omega \varepsilon \varepsilon_{0} \iint \Re_{2}{ }^{*}(\mathrm{y}) . \Delta \mathrm{n}_{2}{ }^{2} \Re_{4}(\mathrm{y}) \mathrm{dy}
$$

Dari persamaan tersebut di atas tampak bahwa besar koefisien kopling sangat bergantung pada medan optik $\mathfrak{R}$, sehingga untuk mendapatkan pengkopelan berkas optik dari pemandu 1 ke pemandu 2 dapat diatur besarnya medan optik $\Re_{2}$ dan $\Re_{4}$,

$$
\begin{aligned}
& \mathfrak{R}_{2}(y)=C[\cos (\gamma y)-\alpha / \gamma \sin (\gamma y)] \\
& \mathfrak{R}_{4}(y)=C[\exp (-\alpha d)] \exp [-\gamma(y+d)]
\end{aligned}
$$

dimana $C$ adalah konstanta normalisasi yang berhubungan dengan orthonormalisasi $\langle\mathrm{m}| \mathrm{k}>=\int \mathfrak{R}_{\mathrm{m}}^{*} \mathfrak{R}_{\mathrm{k}} \mathrm{dy}=\frac{2 \omega \omega}{\beta_{\mathrm{m}}} \delta_{\mathrm{km}}$.

Besarnya daya pada pandu gelombang 1 dinyatakan sebagai $P_{1}(z)=A_{1}(z)$ $A_{1}^{*}(z)$ dan pandu gelombang $2, P_{2}(z)=A_{2}(z) A_{2}^{*}(z)$. A pabila daya masukan diberikan pada pemandu 1 (Gambar 1 ) sebesar $P=P_{1}(0)=\left|A_{1}(0)\right|{ }^{2}$ dan $P_{2}(0)=0$, maka dari persamaan (7) dan (8) didapatkan besarnya distribusi daya pada guide 1 sepanjang arah perambatan $\mathrm{z}$.

\section{PEMBAHASAN}

Ilustrasi dari daya masukkan $\mathrm{P}_{1}(0)$ di dalam pandu gelombang nonlinear fungsi indek bias efektif $\mathrm{N}$ bervariasi terhadap tebal pandu gelombang yang ditunjukkan pada Gambar 3a meru pakan hasil numerik dari persamaan 3, 6 dan 13 dengan parameter pandu gelombang $\mathrm{n}_{1}=\mathrm{n}_{5}=1.54, \mathrm{n}_{2}=1.57, \mathrm{n}_{3}=1.55$ dan $\alpha$ $=4.10^{-11} \mathrm{~m}^{2} / \mathrm{W}$. Pertama, tentukan harga $\mathrm{N}$ awal yang sesuai dengan persamaan (3) dengan memenuhi syarat batas, kemudian dari persamaan (5) didapatkan harga $\mathrm{N}_{2}$. Dengan memasukkan harga $\mathrm{N}_{2}$ ke dalam persamaan (3) akan dihasilkan $\mathrm{N}$ baru, dari hasil ini didapatkan harga $\mathrm{N}_{2}$ baru. Proses ini berjalan berulang-ulang dengan iterasi sampai didapatkan harga $\mathrm{N}$ yang 
konvergen untuk setiap daya masukan $P_{1}(0)$ dan hasilnya seperti ditunjukkan pada Gambar 2a. Dari gambar tersebut tampak bahwa pada titik A, B, C indek bias effektif $\mathrm{N}_{2}$ akan mengalami kenaikkan yang sebanding dengan besarnya kenaikkan daya masukkan sampai di titik $D$ untuk $b=3 \mu \mathrm{m}$. Bila daya masukkan diperbesar sampai di titik E, maka akan terjadi kenaikkan indek bias effektif yang sangat tinggi. Perubahan indek bias efektif ini akan mengakibatkan berubahnya koefisien kopling $\mathrm{K}_{2}$ sesuai persamaan (9), seperti ditunjukkan oleh Gambar 2b yang bervariasi terhadap geometri pandu gelombang. Dari gambar tersebut tampak bahwa akan terjadi penurunan harga koefisien kopling $\mathrm{K}_{2}$ untuk kenaikkan indek bias efektif akibat adanya kenaikan daya masukkan yang bervariasi terhadap tebal b dan jarak antar pandu gelombang $\mathrm{d}$.

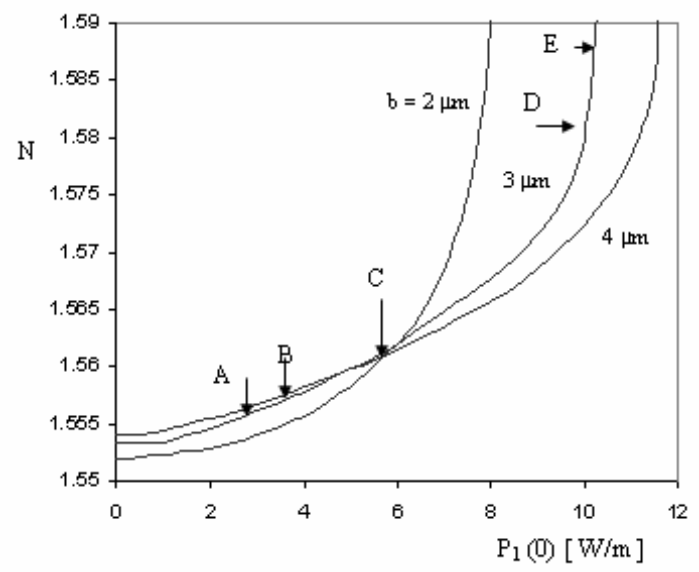

(a)

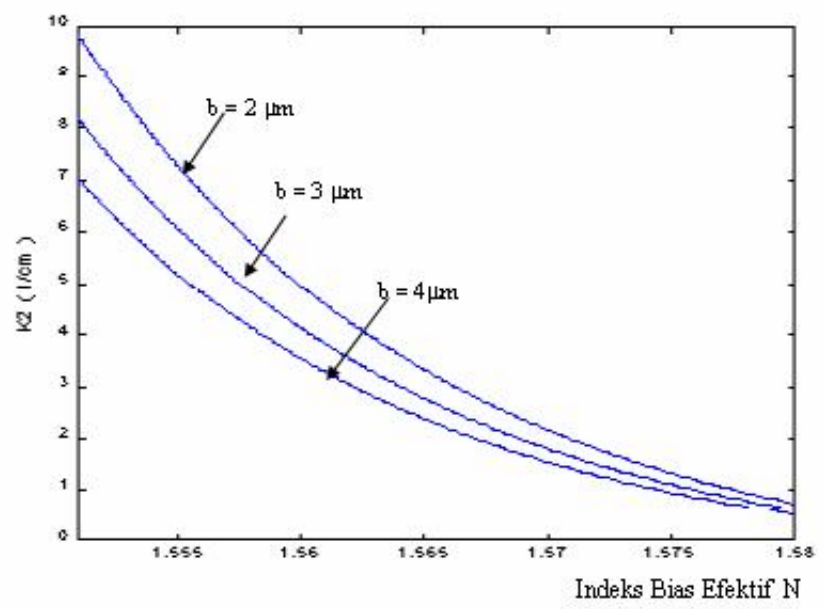

(b)

Gambar 2. (a) Variasi indeks bias efektif propagasi N fungsi dari daya masukan $\mathrm{P}_{1}(0)$, dan (b) Variasi koefisien kopling $\mathrm{K}_{2}$ terhadap $\mathrm{N}$ untuk $\mathrm{b}=2 \mu \mathrm{m}, 3 \mu \mathrm{m}, 4 \mu \mathrm{m}$ dengan $\mathrm{d}=3 \mu \mathrm{m}$. 


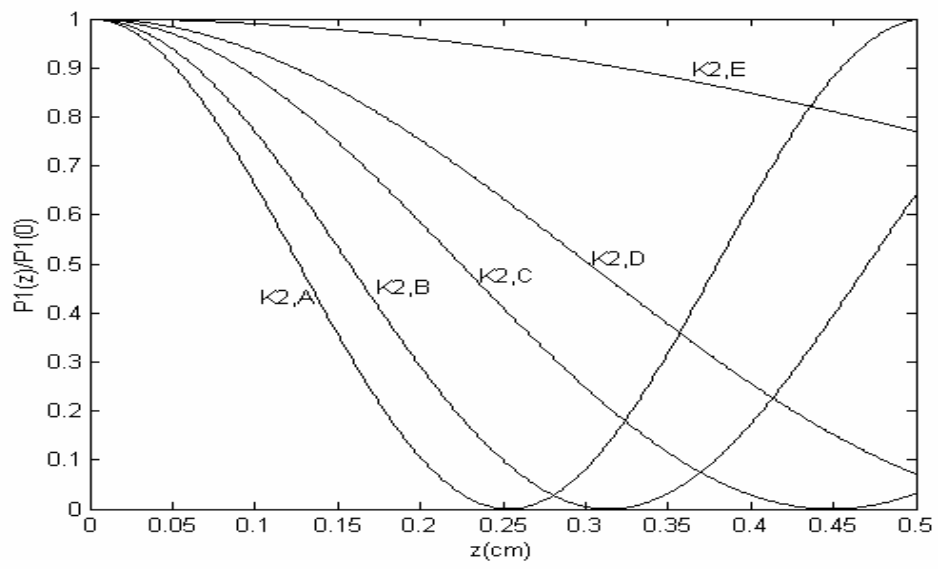

Gambar 3. Grafik perubahan pola propagasi gelombang sepanjang z yang bervariasi terhadap perubahan koefisien kopling $\mathrm{K}_{2}$ di titik-titik $\mathrm{A}, \mathrm{B}, \mathrm{C}, \mathrm{D}$ dan $\mathrm{E}$ sesuai Gambar 3 dan 4 dengan $b=3 \mu \mathrm{m}$

Dengan menggunakan persamaan (9), (10) dan (11) didapatkan pola propagasi gelombang sepanjang $z$ untuk titik - titik $A, B, C, D$ dan $E$ yang mempunyai koefisien kopling masing-masing $\mathrm{K}_{2: A}, \mathrm{~K}_{2: B}, \mathrm{~K}_{2: \mathrm{C}}, \mathrm{K}_{2: \mathrm{D}}$, dan $\mathrm{K}_{2: \mathrm{E}}$ seperti ditunjukkan Gambar 3. Untuk $\mathrm{P}_{1}(0)$ rendah akan tejadi transfer daya optik dari pemandu 1 ke pemandu 2 dengan koeffisien kopling $K_{2}$ pada setiap titik tersebut. Untuk daya masukkan yang cukup rendah seperti ditunjukkan pada titik-titik A, B dan C maka efek pengkopelan dari kedua modus tersebut sangat bergantung pada koefisien kopling $\mathrm{K}_{2: a}, \mathrm{~K}_{2: \mathrm{B}}$ dan $\mathrm{K}_{2: \mathrm{c}}$. Oleh karena itu pada masing-masing indeks bias efektif akan memberikan panjang kopling $L_{c}=0.25,0.32$, and $0.45 \mathrm{~cm}$ dengan koefisien kopling $K_{2: a}, K_{2: B}$ dan $K_{2: c}$ seperti ditunjukan pada Gambar 3. A pabila daya masukan dinaikkan sehingga $P_{1}(0)$ mempunyai harga yang culup besar maka overlap medan dari kedua pandu gelombang tersebut tidak akan terjadi, sehingga efek pengkopelan dari kedua modus tidak akan terjadi yang ditunjukkan oleh titik D dan E. Sehingga pola propagasi gelombang optik didalam struktur pandu gelombang (gambar 1) yang dinyatakan pada persamaan (14) dapat di ilustrasikan dalam bentuk perubahan propagasi sepanjang- $\mathrm{z}$ sebagai fungsi dari perubahan indek bias efektif $N$. Ungkapan diatas dapat dilihat lebih detail pada Gambar 4, dimana untuk panjang kopling $0.25 \mathrm{~cm}$ dan $0.45 \mathrm{~cm}$ masih menunjukkan terjadinya osilasi dari propagasi gelombang antara kedua pemandu dari beberapa daya masukan. Untuk panjang kopling $0.32 \mathrm{~cm}$ akan mengakibatkan terjadi transfer daya dari pandu gel ombang 1 ke pandu gelombang 2 dimana $P_{1}(0)=3.2$ Watt (titik $B$ ) dengan koefisien kopling $\mathrm{K}_{2 \mathrm{~B}}$ dan $\mathrm{P}_{1}(\mathrm{z}) / \mathrm{P}_{1}(0)=0$ (Gambar 3). Bila daya masukan $\mathrm{P}_{1}(0)$ dinaikkan (titik $\mathrm{D}$ ) menjadi 10 Watt maka akan terjadi perpindahan daya optic $P_{1}(z)$ sebesar 5 Watt atau terjadi transfer daya optic sebesar $3 \mathrm{~dB}$, dengan koefisien kopling $K_{2 D}$ dan $\mathrm{P}_{1}(\mathrm{z}) / \mathrm{P}_{1}(0)=0.5$ (Gambar 3). Kenaikan $\mathrm{P}_{1}(0)$ diatas 11 Watt (titik E) akan 
mengakibatkan tidak terjadinya transfer daya, ini berarti gelombang optic tetap tersalur dalam satu pandu gelombang.

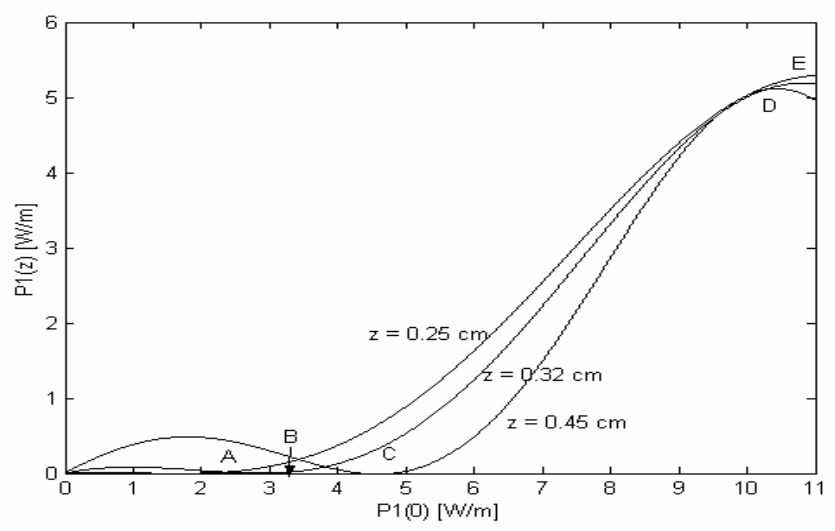

Gambar 4 Distribusi daya dari propagasi gelombang yang bervariasi terhadap panjang propagasi $z$ untuk $b=3 \mu \mathrm{m}$

Dengan demikian untuk panjang kopling $z=0.32 \mathrm{~cm}$ dengan daya masukan yang rendah akan terjadi transfer daya diantara kedua pandu gelombang tersebut, sehingga keluaran berkas optik ke pandu gelombang 2, menghasilkan posisi OFF dipandu gelombang 1. Sedang untuk daya masukan tinggi mengakibatkan posisi $\mathrm{ON}$ dipandu gelombang 1 yaitu pada titik E. Dengan posisi ON dan OFF tersebut, pandu gelombang nonlinear directional coupler dapat bekerja sebagai saklar optik yang berfungsi sebagai gerbang AND dan $O R$.

\section{SIMPULAN}

Dua pandu gelombang dengan bahan optik nonlinear, tampak bahwa besarnya perubahan koefisien kopling yang sangat bergantung pada daya masukan dapat dianalisa melalui pemisahan variabel dari persamaan eigennya yang akan melibatkan solusi spatial soliton pada komponen nonlinearnya. Koefisien kopling antara kedua pandu gelombang tersebut di analisa melalui solusi linear dengan indek bias efektif yang berubah sesuai besarnya daya masukan. Dari hasil numerik tersebut tampak dengan jelas bahwa devais tersebut dapat dipergunakan sebagai all-optical switching.

\section{PUSTAKA}

[1] Chiang, K.S. (1986) J. A pplied O ptics, Vol. 25, No. 3, 348-354.

[2] Chiang, K.S., dan Sammut, R.A (1993) J. O pt. Soc. A m. B, Vol. 10, No. 4, 704-708.

[3] Harsoyono (2000) Chiang M ai J. of Science, Vol. 27, No. 1, 24 - 32.

[4] Harsoyono (2002) Chiang M ai J. of Science, Vol.29, No. 2, 95-102. 
[5] Harsoyono, Siregar, R.E., dan Tjia, M.O. (2002) J. N onlinear O ptical Physics and M aterals, Vol. 10, No.2, 233-247

[6] Harsoyono, Siregar, R.E., Tjia, M.O., Sombra, A.S.B. (2003) Journal of Optics Communications, Vol. 221, No. 1-3, 63-71.

[7] Jensen S.M. (1982) IEEE-J. Quantum Electronics, Vol. QE-18, No. 10, 1580-1583.

[8] Li, Q.Y., Pask, C, dan Sammut, R.A. (1991) O ptics Letters, Vol.16, No.2, 10831085.

[9] Nobrega, K.Z., da Silva, M.G., Sombra, A.S.B (1999) J. O ptical Communications, Vol. 20, No. 6, 210-214. 